\title{
Foto-Elicitación e indagación narrativa visual en estudio de casos y grupos de discusión
}

\author{
Laura Rayón Rumayor ${ }^{1}$, María Jesús Romera Iruela², \\ Ana María de las Heras Cuenca ${ }^{2}$, Alba Torrego González ${ }^{2}$ \\ y Antonio Bautista García-Vera ${ }^{2}$
}

\author{
${ }^{1}$ Departamento de Ciencias de la Educación, Universidad de Alcalá | laurarayon@uah.es | \\ https://orcid.org/0000-0003-0339-8221 \\ ${ }^{2}$ Departamento de Estudios Educativos, Universidad Complutense, Madrid | \\ mjromera@ucm.es | https://orcid.org/0000-0001-8922-5828 | delasheras@ucm.es | \\ |https://orcid.org/0000-0001-5259-1218 | altorreg@ucm.es | https://orcid.org/0000-0002- \\ 4083-8727 | bautista@ucm.es | https://orcid.org/0000-0002-5194-7419
}

\begin{abstract}
Resumen: La foto-elicitación y la indagación narrativa visual son procesos metodológicos novedosos con un desarrollo escaso en España, siendo introducidos en el ámbito de la educación por el grupo de investigación Desarrollo Tecnológico, Exclusión Social y Educación que realiza su actividad en la Universidad Complutense de Madrid (España). Presentamos una delimitación conceptual y metodológica de los mismos, mostramos su aplicación en dos estudios de caso en los que hay presencia de discusión grupal. Analizamos las potencialidades de ambos procedimientos para la investigación con estudio de casos y grupos de discusión, y las limitaciones. Su aportación de información más profunda con experiencias, pasadas y presentes, sentimientos y recuerdos, unido a la indagación colaborativa que ellos hacen posible, les confiere un valor metodológico en la investigación y las prácticas profesionales de los docentes. Concluimos, destacando su valor y contribución al campo de la educación, a su conocimiento pedagógico y a la mejora de la práctica educativa.
\end{abstract}

Palabras Clave: Educación; Foto-elicitación; Indagación narrativa visual; Grupos de discusión; Estudios de caso.

\section{Introducción}

El uso de registros audiovisuales en la investigación educativa familiarmente ha consistido en introducir la cámara en el trabajo de campo para que los investigadores recogieran datos para aportar realismo sobre las realidades objeto de estudio. Desde la Antropología y la Sociología, hace ya tiempo que se puso en duda esta función ilustradora, y se identificó otra función de los dispositivos audiovisuales en la investigación. Además del uso de estos recursos para el almacenamiento, ilustración y descripción de las prácticas sociales, la cámara se contempló como dispositivo para que los actores sociales narrasen sus historias y expresasen su punto de vista de forma reflexiva, favoreciéndose, así, su participación en la investigación (Ardèvol, 2006; Pink, 2013; Banks, 2007).

Además, el desarrollo tecnológico invita a incorporar la utilización de las imágenes en la investigación cualitativa, dado su potencial para la recepción crítica y para su análisis en distintas situaciones. Nos encontramos en la era de la convergencia (Jenkins, 2008), en la que los nuevos y los viejos medios se entremezclan, la hibridación de las funciones permite construir nuevos discursos multimodales y la convergencia y combinación de diferentes lenguajes otorga relevancia a lo simbólico o icónico. La cultura de la imagen está cada vez más presente y, con ello, la realización de las fotografías con diferentes dispositivos, práctica habitual y cotidiana que trasciende lo individual para ser compartida en múltiples plataformas y soportes.

El interés por el uso de la fotografía en la investigación en las Ciencias Sociales va adquiriendo relevancia gracias a los trabajos de referencia de Panofsky (1995) y Barthes (1994) sobre su valor semiótico. Estos autores entienden la fotografía como un sistema de representación que puede combinarse con el lenguaje verbal o textual, lo que abre un camino de posibilidades para transitar hacia formas de investigaciones participativas y creativas. 
Desde estas consideraciones previas, en varios proyectos de investigación (EDU200803218EDU, EDU2011-23380, EDU2014-57103) hemos analizado el uso de la fotografía y, con ello, nuevos caminos para apresar, captar y comprender las realidades educativas. Los objetivos del capítulo responden al trabajo empírico del grupo de investigación Desarrollo Tecnológico, Exclusión Social y Educación (DETECESE). Pretendemos dar a conocer el valor de la foto-elicitación para la investigación con estudio de casos y la aportación de la narración fotográfica en los grupos de discusión. Procedimientos que venimos explorando desde hace doce años y serán detallados en relación con la descripción de dos proyectos de distinta naturaleza para cubrir la doble vertiente heurística y didáctica. En el primero se ha introducido la foto-elicitación en el Practicum de la formación inicial del profesorado (Bautista, 2016/2017). El segundo se orienta la generación de conocimiento en el campo de la Educación Intercultural (EDU200803218EDU).

En este capítulo comenzamos conceptuado la foto-elicitación con sus diversos enfoques y examinamos su utilización y sus contribuciones a la metodología de estudios de casos. Nos situamos, siguiendo a Schwandt y Gates (2018), en la visión colectiva de esta forma de investigación, que "existe para abordar la dialéctica que se subyace en el centro de la comprensión - una investigación en marcha de lo empírico para refinar lo teórico y de lo teórico para comprender y explicar mejor lo empírico" (p. 354). Proseguimos, con una conceptualización de la narración fotográfica y examinamos su valor en relación con el grupo de discusión. Asumimos que el grupo es un espacio de interacción entre los participantes en la investigación, un marco de acción privilegiado para la construcción de narraciones fotográficas colectivas.

\subsection{La foto-elicitación y la narración fotográfica en el campo de la Educación}

La vinculación de la fotografía con las formas verbales expresivas del sentido que tiene la misma para un sujeto encuestado en un proceso de investigación ha dado lugar a un nuevo procedimiento, denominado foto-elicitación. Su incorporación en la investigación y práctica de la educación es más reciente todavía, al igual que sucede en otros campos científicos. Uno de los ámbitos en donde más se ha desarrollado la foto-elicitación es la intervención socio-educativa y en el mismo se desarrolla el trabajo empírico de nuestro grupo de investigación. En la revisión de Harper (2002) sólo se mencionan dos trabajos educativos que la utilizan, si bien se ha producido un desarrollo posterior, que pasamos a conceptualizar y a esbozar.

\subsubsection{Foto-elicitación}

La literatura especializada en el tema reconoce como seminal el experimento de Collier (1957), que incorporó la fotografía a las entrevistas y comparó su resultado en relación con el obtenido por otras realizadas sin utilizar imágenes. Asimismo, constituye un hito el trabajo de delimitación y desarrollo de la foto-elicitación que, muchos años después, realizó Harper (2002), quien manifestó que la misma está basada "en la simple idea de insertar una fotografía en una entrevista de investigación" (p.13). Próximo a nuestros días, Wright (2016) ofrece, en el tratado de fotografía, una conceptualización similar, al afirmar que "la foto-elicitación puede describirse como la explotación deliberada de la respuesta del espectador a la fotografía" (p.154) o también, como "el uso de imágenes para instigar una respuesta de las personas como parte de un método de investigación estructurado" (p.174).

Desde nuestro punto de vista, este procedimiento supone la vinculación de técnicas de recogida de datos, propias de los métodos de la observación y la encuesta. En el mismo se articulan dos formas de presentación y comunicación de aspectos la realidad, imagen y palabra, que posibilitan una captación y comprensión de los mismos más adecuada y plena. De acuerdo con Harper (2002), las imágenes evocan elementos más profundos de la conciencia humana que las palabras, por consiguiente, la foto-elicitación, además de 
suscitar sentimientos y recuerdos, produce información de naturaleza diferente, de mayor riqueza, desde una honda conversación significativa y relevante. Además, amplía las posibilidades de la investigación empírica convencional, al dar validez y fiabilidad a las entrevistas y permitir superar las dificultades que se plantean en las que se realizan a nivel profundo, dado que, al estar ellas ancladas en imágenes, éstas son entendidas, al menos en parte, por el investigador y los encuestados, llevándoles a un entendimiento común, mediante la apertura de sus perspectivas o el establecimiento de puentes entre sus culturas. Asimismo, hay que destacar la indagación colaborativa que el mencionado procedimiento inspira (pp. 15, 20-23).

En el despliegue de la foto-elicitación han surgido, según la sistematización de Lapenta (2011), tres enfoques junto al original. Estos son: fotografía reflexiva o foto-elicitación autoconducida, fotovoz y producción colaborativa o participativa de imágenes.

Si relacionamos el potencial esbozado de la foto-elicitación con el enfoque del estudio de casos, se evidencia la aportación que supone su incorporación para el logro de una comprensión profunda de la unicidad del caso objeto de la investigación, al posibilitar la ampliación de la conciencia de los fenómenos, ahondando en sus cualidades, dando cabida a la experiencia compartida y relacionándola con otras formas de conocimiento, desde el diálogo crítico e intersubjetivo. De esta forma, la foto-elicitación contribuye al logro de los propósitos a los que se destina el estudio de caso, cuyos usos indicados por Schwandt y Gates (2018) son: descripción, generación de hipótesis o desarrollo de teorías, prueba de hipótesis y teorías, así como contribución hacia el avance de la teoría normativa.

En el ámbito de la educación se ha utilizado la foto-elicitación y, también, en el estudio de caso como forma de investigación. En una búsqueda bibliográfica efectuada en las principales bases de datos hemos identificado unos 65 documentos con la intersección de las palabras foto-elicitación, estudio de casos y educación. En nuestro análisis de los mismos hemos constatado el valor de la aplicación de dicho procedimiento y dejamos constancia, tan sólo, de algunas aportaciones. Así, la foto-elicitación ha incrementado la conciencia de las prácticas del profesorado, ha producido re-asignación de significados en las mismas con sus correspondientes cambios, ha explicitado las creencias, teorías y valores que subyacen a la acción educativa, ha contribuido a la comprensión profunda de los fenómenos indagados, ha incorporado las voces silenciadas en la investigación, y ha abierto nuevas perspectivas en los objetos de estudio, posibilitando la teorización sobre ellos, entre otras contribuciones (Bautista, Rayón, \& de las Heras, 2020; Boucher, 2018; Grimmet, 2018, a título de muestra documental).

\subsection{La indagación narrativa visual}

Los métodos visuales narrativos actualmente son temas de interés en Ciencias Sociales, pues se reconoce que la imagen tiene el potencial de evocar una comprensión empática de las maneras que tienen otras personas de experimentar sus mundos (Rose, 2001).

La indagación narrativa visual consiste en que un sujeto genere un relato sobre acontecimientos vividos o sobre alguna idea argumento a partir de la proyección de una imagen o conjunto de imágenes (Bach, 1998; Lemon, 2006). Los sujetos expresan sus subjetividades y vivencias a través de su discurso verbal e, icónicamente, a partir de las imágenes contenidas en las fotografías (composición de la imagen, plano, angulación, selección de objetos, sujetos y escenarios). Se genera un proceso narrativo que, según Etherington (2007), tiene la virtualidad de exponer una situación o hecho hacia adentro, pero también hacia afuera, hacia atrás y hacia adelante, un viaje cognitivo en el que pueden encontrar nuevas preguntas e hipótesis que permiten profundizar y comprender mejor una situación, concepto, o realidad.

Es interesante su uso en los ámbitos de la salud y la terapia (Han \& Oliffe, 2016; Knowles \& Cole, 2008). Por ejemplo, los pacientes afectados por un cáncer pueden reflexionar sobre su enfermedad y tomar consciencia de su propia identidad para afrontar sin estrés el día a día (McNutt, 2013), o potenciar el autocontrol de pacientes con riesgo cardiovascular ante las situaciones estresantes que viven, ya que la imagen permite 
establecer vínculos causales entre eventos secuenciales para crear significados (Williams, Anderson, Barton, \& McGhee, 2012). En el ámbito de la investigación psicosocial, la indagación narrativa se ha empleado para trabajar la auto-etnografía con trabajadoras sexuales (Smith, 2015), promover la reflexión con personas que viven en ambientes vulnerables (Copes, Tchoula, Brookman, \& Ragland, 2018), o acceder a la experiencia de personas sin hogar en situaciones de adicción para proponer mejoras en la atención primaria (Sestito et al., 2017). Se ha utilizado también para dar voz a las mujeres que han sufrido violencia de género, involucrarlas en la investigación y darles un papel activo en el proceso (Aldridge, 2013).

En el campo de la educación destacan, entre otros, los trabajos de Moss $(2010,2011)$ y Moss, Deppeler, Astley y Pattinson (2007), centrados en el uso de la narración con medios visuales para promover la inclusión educativa del alumnado diverso. El trabajo de Allen y colaboradores (2020) está orientado a que lo niños pueden desarrollarse personal y socialmente, hacer conexiones culturales a través de la fotografía y narrativas para imaginar otras posibilidades para sus vidas. Los trabajos pioneros de Bautista $(2009,2010$, $2013,2017,2019)$, plantean el potencial de la narración con el lenguaje de la fotografía para la comprensión de los humanos y de los acontecimientos que rodean al grupo que narra. Este autor identifica la narración fotográfica como la base de una educación intercultural porque en el proceso de narración los miembros de un grupo, estudiantes (Bautista, Rayón, \& de las Heras, 2012) y familias (Bautista, Limón, Oñate, \& Rostand, 2016), plantean contenidos de historias, confrontan pareceres sobre los elementos visuales a emplear, acuerdan la estructura narrativa y, sobre todo, tienen oportunidades de conocerse y comprender sus diferencias, y por tanto, de comenzar a apreciarse. Autores como Carrington, Allen y Osmolowski (2007) se han centrado en conocer cómo las narraciones audiovisuales favorecen la elaboración de un currículum inclusivo y entornos educativos que eviten la exclusión social del alumnado más desfavorecido.

En las revisiones realizadas encontramos un elemento común: un acontecimiento se torna en experiencia cuando se convierte en relato, y esa narración se convierte a su vez en una nueva experiencia cognitiva y emocional que genera una nueva acción, fundamento de la transformación personal. Son los trabajos desarrollados en el ámbito de la educación los que inciden no solo en la transformación personal de los participantes, también en la transformación social del grupo. Valoramos la importancia que se otorga al proceso de narración para el fomento de intercambios, debates y contraste de pareceres entre los miembros de un grupo. Se contempla el desarrollo personal, pero sin desestimar que la indagación narrativa es un proceso de participación, encuentro entre personas para favorecer la comprensión de otros puntos de vista, y el entendimiento mutuo.

Se trata de un proceso que amplía nuestra capacidad como investigadores para explorar y comprender la experiencia de los participantes, y por tanto, la realidad social. Es esta dimensión que estamos explorando mediante la aplicación de la narrativa fotográfica en el grupo de discusión. Valoramos especialmente el uso de relato fotográfico como un punto de partida para acceder a conversaciones y diálogos genuinos, y con ello al entendimiento sobre cómo experimentan y entienden el mundo que habitan los participantes. ¿Qué aportaría la narración fotográfica a los grupos de discusión tal y cómo la entendemos según lo expuesto anteriormente? ¿Puede aportar alguna idea nueva y distintiva?

Los trabajos de Barbour (2013), los pioneros de lbáñez (1986, 1992), y los de Marková, Linell, Grossen y Salazar (2007) sobre el grupo de discusión en la investigación social, plantean que los participantes son siempre sujetos que cambian al conversar porque cada participante habla y puede responder, y a su vez, el que responde puede cuestionar y volver a hacer otras preguntas para la construcción de un discurso grupal como una totalidad (Cano, 2008). Desde estos planteamientos, las bondades que el uso de los relatos fotográficos aporta al grupo de discusión son:

a) La evocación y registro de datos para acceder a una comprensión de la realidad objeto de estudio que va más allá de lo que es posible solo con la palabra.

La fotografía cuando se convierte en relato revela ideas, emociones y experiencias a las que los investigadores no podrían acceder con otras técnicas (Ardèvol, 2006; Pink, 2007; 
Banks, 2007; Rayón \& de las Heras, 2012). Estos trabajos evidencian que la fotografía favorece el extrañamiento de los participantes ante la realidad cotidiana. A través de la fotografía se concretan los referentes, se facilita pasar de la idea a la acción; a un acto ilocutorio (Austin, 1981) donde se comparte una realidad. De esta forma, se facilita la decodificación y se construye una narración basado en lo visual, aprovechando todas las dimensiones presentes en un discurso multimodal donde el mensaje nos llega a través de distintos sistemas de representación.

b) Revierte las relaciones de poder entre investigadores y participantes (Ibáñez, 1986) al exigir establecerse un procedimiento de trabajo que, como hemos visto, requiere de relaciones horizontales entre participantes e investigadores. Las fotografías tomadas por los participantes son los ejes vertebradores del diálogo que se establece en el grupo. Las situaciones, conceptos o ideas que connotan esas imágenes ganan visibilidad frente a la visión y posicionamiento de un agente externo que podría condicionar el discurso (Porto \& Ruiz, 2014). Así, el papel del investigador se concreta como un dinamizador del diálogo, cuya contribución principal reside en conectar los diferentes discursos evocados, así como recoger y contrastar diferentes puntos de vista e ideas contradictorias que expresan los participantes. Ello ayudaría a mitigar uno de los peligros enunciados por Ibáñez (1986) y Barbour (2013), la posibilidad de que los participantes construyan un discurso por deseabilidad social; es decir, que expresen lo que el investigador quiere oír.

c) La fotografía hecha narración tiene la virtud de ubicar en los contextos cotidianos al autor de la fotografía (Bach, 2007) y, consecuentemente, contemplar una dimensión clave en el grupo de discusión: la captación de los procesos cotidianos de la vida humana y así apresar los significados de la vida social. En el grupo de discusión, tal y como lo concibió lbáñez (1992), el lenguaje se transforma en acción, en un proceso de autoconocimiento y autoconciencia para el grupo que narra sobre el orden social que se materializa precisamente en el lenguaje. La narración fotográfica funcionaría de anclaje en lo cotidiano, el habla surgiría de temas o situaciones concretas y no ajenas al grupo que narra, reforzando uno de los fines del grupo de discusión, servir como dispositivo de emancipación para el grupo.

d) Otras bondades se concretarían en compensar la artificialidad en relación con técnicas basadas en el lenguaje verbal, y el aburrimiento y distanciamiento social que puede generarse en un grupo de discusión. La fotografía añade a la conversación un referente creativo, motivador, y desencadenante no solo de ideas, también de emociones y sentimientos.

\section{Los procedimientos de foto-elicitación e indagación narrativa fotográfica}

Estos procesos presentan una cierta diferenciación según el marco epistemológico orientador de las investigaciones en las que se inscriben que, a su vez, marca su enfoque que se refleja en las decisiones acerca de las fotografías.

\subsection{El procedimiento de foto-elicitación}

Si bien en la bibliografía especializada encontramos modelos que difieren en el número de etapas, aunque son equivalentes, aportamos, en base a la investigación precedente, el proceso general, en toda su amplitud, que consta de las siguientes fases:

1. Identificación de la cuestión objeto de estudio por el investigador, o por su equipo, y contacto con los participantes orientado a su vinculación con el proyecto.

2. Planificación del proceso de recogida de datos: consentimientos informados para la toma de las fotografías y para su uso; número y orientación temática de las fotografías, tiempo para su realización, cronograma de las sesiones de foto-licitación, provisión de medios materiales y asignación de tareas, fundamentalmente. 
3. Formación o introducción en el enfoque de la foto-elicitación a los participantes.

4. Realización o recopilación de las fotografías.

5. Sesiones de entrevista con visionado de las fotos y suscitación del discurso de quien ha realizado las imágenes, o de sus destinatarios, para expresar su significado y sentido desde el diálogo con los participantes en las mismas. En algunos casos y modalidades de foto-elicitación, al final de las entrevistas se pide, también, a quien ha evocado el discurso, que seleccione, ordene o clasifique las fotos. Ahora las preguntas del investigador se orientan al logro de una indagación profunda mediante ulteriores narraciones. Así, en continuidad con la foto-elicitación se origina la indagación narrativa. Todo este proceso se graba para tener un registro del mismo.

6. Análisis e interpretación de los datos: desde las transcripciones de las grabaciones, a veces incluyendo las fotografías, se aplica el procedimiento de análisis cualitativo que el enfoque de la investigación precise.

7. Conclusiones, elaboración de informes y difusión de los resultados.

\subsection{El procedimiento de indagación narrativa fotográfica}

En las revisiones sobre la narrativa visual, encontramos dos procedimientos principales para aplicarlos en grupos de discusión: Uno, que la fotografía o conjunto de ellas sean creadas, seleccionadas y propuestas por el propio investigador; el otro, que sean los participantes del grupo de discusión quienes realicen sus propias fotografías, las seleccionen y propongan como objetos de narración (Banks, 2007; Mannay, 2017; Pink, 2007). Nos interesa la dimensión participativa y reflexiva de los métodos visuales que se permite en el segundo procedimiento. El hecho de hacer fotografías por parte de los participantes no es únicamente una manera de extraer información, sino una forma de reflexionar, intercambiar, fomentar la participación, el debate y de visibilizar situaciones problemáticas de los participantes. Se parte, así, de un planteamiento investigador orientado hacia la transformación social y el empoderamiento de los grupos (Serrano, Revilla, \& Arnal, 2006).

En las sesiones de trabajo, a partir del material fotográfico recopilado por los miembros de un grupo, se procede a analizar y debatir el significado que tiene cada fotografía para ellos. Es el momento de seleccionar e identificar las más relevantes, y de dotar de significado compartido a cada fotografía. Tras este trabajo previo, uno de los miembros organiza la disposición de las mismas para generar el relato. El resto de participantes, después, tomarán la palabra para analizar, matizar, y valorar el relato inicial. Es el momento de negociación de significados entre los participantes y de reorganizar las fotografías. Ello deviene en la reconstrucción de significados que lleve paulatinamente a una narración final consensuada. Esta forma de trabajar la hemos desarrollado con estudiantes de Educación Primaria.

La segunda forma de organizar el grupo de discusión es que sea un miembro del grupo en el que seleccione, organice y muestre las fotografías y construya la narración. A partir de ahí, el resto de los miembros tomarán la palabra para enriquecer el relato inicial, aportando sus propias fotografías que formarán parte del material fotográfico final. Incluso el investigador como observador externo puede interpelar, cuestionar o preguntar para conducir al grupo de discusión a profundizar en determinados conceptos, ideas o problemas que sean objeto de interés para la investigación.

Lo importante de estos procesos no es tanto la narración como producto final, sino la transformación de unas imágenes tangibles, conceptualmente densas, en un relato inicial para transitar hacia un relato conformado por la voz colectiva. La indagación sobre los significados asociados a las fotografías realizadas, permite construir un relato con sentido para todos los participantes, un proceso desde el punto de vista cognitivo y social rico y potente. La fotografía como medio de evocación en la fase de foto-elicitación, da lugar un proceso de construcción de conocimiento participativo, un relato consensuado, tal y como queda reflejado en la figura 1. 


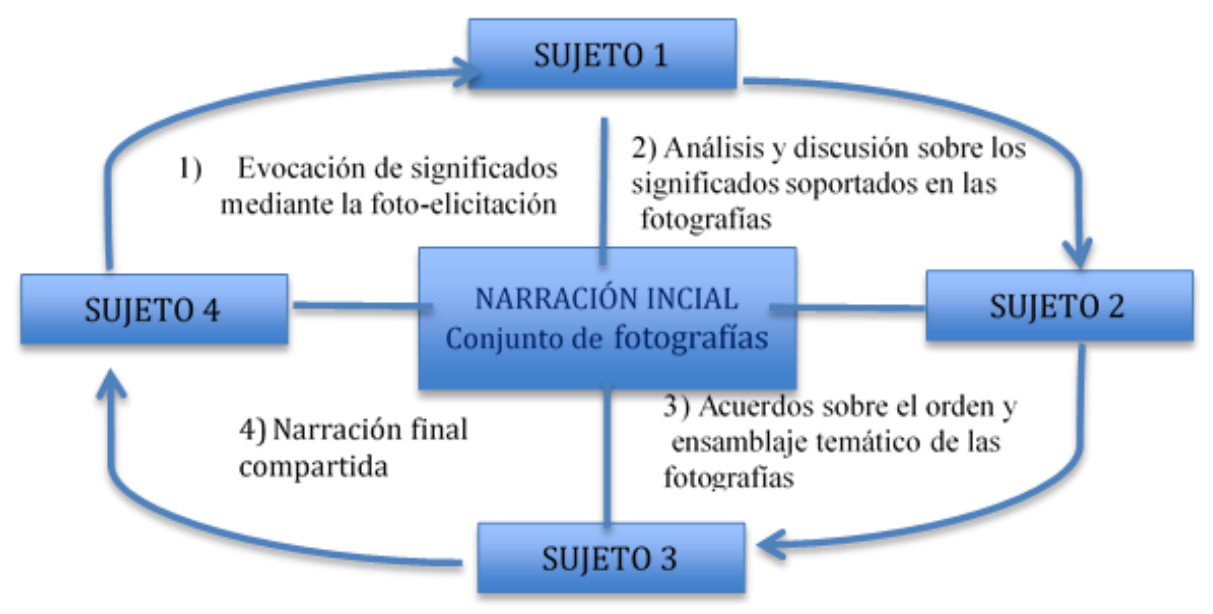

Fig. 1. La producción de la narración fotográfica en el grupo de discusión

Fuente: Elaboración propia

El objetivo de la técnica es analizar cómo los miembros de un grupo elaboran el discurso a partir de la proyección de las fotografías y su organización. Interesa analizar cómo aportan sus propias perspectivas, cómo las ilustran y jerarquizan, y las ponen en relación con dichas fotografías. Ello permite acceder a un conocimiento de la realidad objeto de estudio socialmente construido por el grupo.

\section{Trabajo empírico desarrollado incorporando la fotoelicitación y la indagación narrativa}

Presentamos, a continuación, los dos proyectos de diferente naturaleza realizados y en los que se han aplicado los referidos procedimientos.

\subsection{Proyecto de innovación docente mediante la introducción de la foto-elicitación en el Practicum del Grado de Maestro}

Estudio de caso centrado en la formación, mediada por foto-elicitación, de una alumna del Grado de Maestro durante los 3 meses de estancia en un centro de Educación Infantil y Primaria de Madrid, de carácter público, en el que realiza su Practicum docente.

El objetivo fue conocer si la incorporación de foto-elicitación en su Practicum ayudaba a la alumna a presentar, comunicar y reflexionar sobre sus experiencias, posibilitando la mejora de su formación docente por relacionar e integrar las mismas con sus recuerdos, sentimientos, conocimientos y valores vividos en las situaciones educativas escolares y en las sesiones propias de la metodología con la que se innova.

El proyecto se origina en una universidad madrileña en la que desempeñan su actividad docente los profesores del grupo de investigación y en un Centro de Educación Infantil y Primaria del mismo municipio. La elección del último se hizo al azar desde un proceso basado en la red de instituciones de prácticas, en los asignados a dichos profesores y en su aceptación a colaborar en el proyecto. La profesora mentora del centro educativo fue seleccionada teniendo presentes tres criterios: ser funcionaria, aceptar participar y nivel educativo docente. La alumna universitaria fue la que había elegido ese centro y accedió a la innovación. Tanto la mentora como la alumna se incorporaron al proyecto.

Se obtuvieron los consentimientos informados de los padres de esos niños y del colegio. 
Se solicitó a la alumna que tomara algunas fotografías de los sucesos, comportamientos - las tareas más relevantes durante la semana previa a cada una de las sesiones de fotoelicitación. Éstas se celebraron cada tres semanas, teniendo una duración entre 45 y 60 minutos.

Se hizo una previsión de medios materiales necesarios (teléfonos móviles con cámaras y grabadoras, ordenadores, impresoras, fundamentalmente) y se estableció el cronograma con la asignación de tareas de forma consensuada entre los participantes.

La formación se efectuó introduciendo en la foto-elicitación auto-dirigida a la alumna y a su profesora-mentora del centro educativo, estando a cargo el director del equipo de investigación.

La alumna realizó las fotografías siguiendo las indicaciones mencionadas y se las facilitó a su mentora. Asimismo, se las envió al director del proyecto, quien, a su vez, se encargó de hacerlas llegar a los miembros del grupo de investigación.

En las sesiones de entrevistas fotográficas estuvieron presentes la alumna, su mentora y dos profesores del grupo de investigación. Se visionaron las fotografías en el orden en el que las había hecho la alumna y, para cada una, ésta tomó la palabra, en primer lugar, para hablar con y sobre ellas.

A continuación, los profesores suscitaron el discurso de la alumna y su tutora con respecto a la motivación en la realización de las imágenes, dudas o dilemas que les planteaban, fundamento de las acciones o la toma de decisiones y, en definitiva, sobre el significado y el sentido que tenían para ellas. Los profesores también les hicieron preguntas sobre el contenido de las fotografías.

Los datos se recogieron vinculando dos técnicas propias: la observación participante y la entrevista, con registros fotográficos y guion de la entrevista semiestructurada como instrumentos. Se efectuó una grabación en audio de estas sesiones de foto-elicitación.

Desde la transcripción de las entrevistas, se analizaron los datos mediante el análisis de contenido, utilizando, si existían, las categorías establecidas en trabajos previos y, en su defecto, procediendo, siguiendo a Barbour (2013) y Rapley (2014), en el establecimiento de las mismas fundamentándolas en los datos obtenidos, realizando éste bien de forma consensuada por profesores, alumna y mentora, o bien por el grupo de investigación y, posteriormente, con validación del resto de los participantes.

Así, para las motivaciones en la realización de fotografías se utilizaron las dos categorías establecidas por Bautista (2013a): instrucción y formación, con la delimitación efectuada. La información recogida en las fotografías se analizó desde la conocida tipología de Barthes con sus tres niveles: connotativo o físico-referencial, denotativo o significativo y afectivo. En otros aspectos del contenido se procedió por la vía inductiva señalada.

En cada una de las fotografías consideramos los siguientes aspectos: 1) contenido de la foto (personajes, acciones o situaciones); 2) análisis del discurso: mentora (teorías, creencias, actitudes, hábitos); 3) conocimiento del alumnado del aula (intenciones de las acciones, interpretación de las acciones de otros); 4) finalidad de la fotografía (categorías mencionadas); 5) Naturaleza de la información evocada (clases indicadas); 6) Propuestas de intervención; 7) otros aspectos de la intervención de la alumna en el Practicum. Luego, se hizo la interpretaron los datos a la luz del examen de la bibliografía.

En la figura 2 hemos esquematizado las etapas básicas del proyecto. 


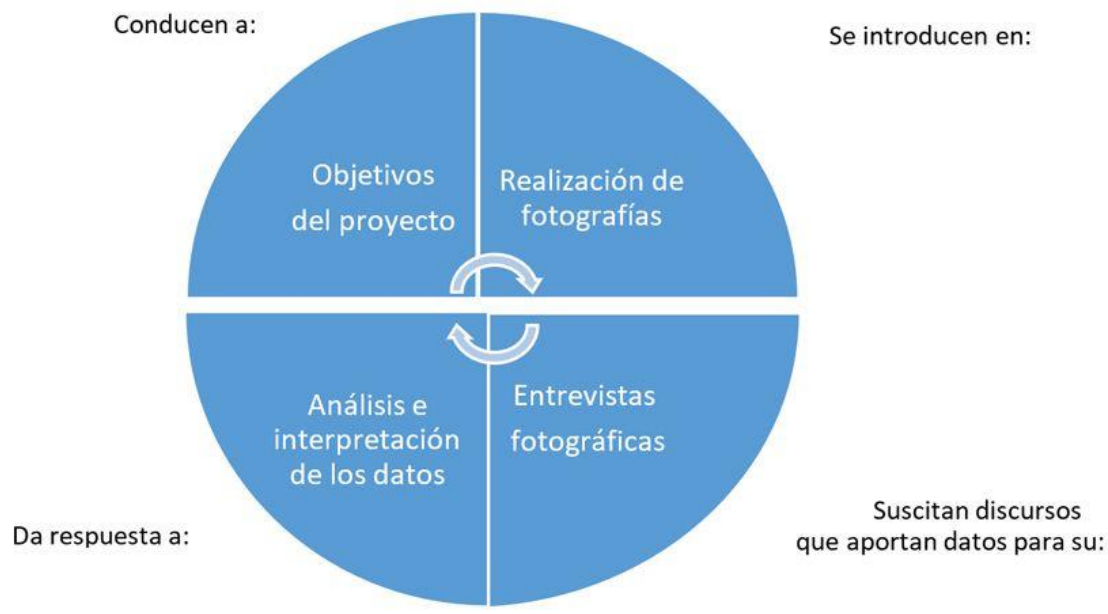

Fig. 2: Representación de las etapas básicas del proyecto

Fuente: Elaboración propia

La conclusión general del proyecto es que la foto-elicitación proporcionó a dicha alumna nuevos significados de los componentes de sus prácticas, como fruto de pensar lo vivido y ayudó a su tutora a tomar conciencia de sus teorías y creencias sobre su enseñanza y el aprendizaje. A nivel más concreto, la foto-elicitación, como procedimiento educativo, ha posibilitado a la alumna la selección y fijación de situaciones instructivas y formativas que desconocía y estimaba valiosas, bien por su carácter metodológico, bien por llevar al logro de objetivos educativos pretendidos. Asimismo, ha fomentado su capacidad de análisis, de reflexión y de búsqueda de soluciones ante las dificultades de los alumnos o los cambios de comportamientos. Junto a ello, ese tiempo del Practicum ha permitido a la alumna sumergirse en las experiencias promovidas en las sesiones de foto-elicitación y participar en los procesos de cambio y mejora de su mentora del centro educativo. Por último, destacamos que la contribución de la foto-elicitación en las prácticas realizadas en el colegio por la futura maestra reside en la unión de teoría y práctica, porque ella y su tutora han mejorado los análisis y reflexiones sobre su experiencia educativa.

El informe de este proyecto se entregó a la universidad en la que prestan servicio los profesores del grupo de investigación. Sus resultados tienen su difusión en congresos y publicaciones.

\subsection{Narración fotográfica en grupos de discusión para favorecer la educación intercultural}

En líneas generales, este proyecto tiene como base los procesos de foto-elicitación que se han conceptualizado en la primera parte del capítulo, procesos sustentadores de la narración fotográfica en el grupo de discusión. La investigación "Narraciones visuales y relaciones interculturales en educación", ha tenido el objetivo de identificar cómo se conforman las relaciones entre los estudiantes, diversos culturalmente, y comprender el potencial formativo de las narraciones fotográficas para favorecer la educación intercultural en la Educación primaria (Bautista, 2012).

Se lleva a cabo el proyecto en dos centros educativos, seleccionados por acoger un alto porcentaje de alumnado diverso culturalmente; uno, un colegio del centro de Madrid; el otro, un colegio de una localidad de Guadalajara que en los últimos años había experimentado un crecimiento demográfico significativo de familias inmigrantes. 
A partir del consentimiento informado por parte de las familias y la explicación previa al alumnado sobre las formas de proceder con las cámaras fotográficas, entramos en la fase de inmersión en el campo que se destina a la elaboración de las narraciones construidas con las fotografías tomadas por el alumnado de Educación Primaria. Los tópicos generadores de las narraciones son: Cómo me veo y como me ven mis compañeros; qué me gusta y no me gusta del cole; este es mi barrio; esta es mi familia; reportaje del verano; reporteros en el recreo; entrevista a mujeres importantes; y una autobiografía escolar.

El proceso de creación de las narraciones se articula así: 1) Reflexión previa sobre el tópico (fase preparatoria de la narración), donde se responde a la pregunta: ¿qué quiero fotografiar-filmar? 2) Toma de fotografías en diferentes contextos, según tópico. 3) Selección de las imágenes más relevantes para cada alumno y puesta en común en el grupo: Debate y discusión de significados. Planificación y ordenación de la narración colectiva. 4) Montaje visual de la narración.

El proceso de construcción de las narraciones fotográficas se vincula a un procedimiento de investigación básico, la imagen como espacio para construir significados compartidos (Figura 3).

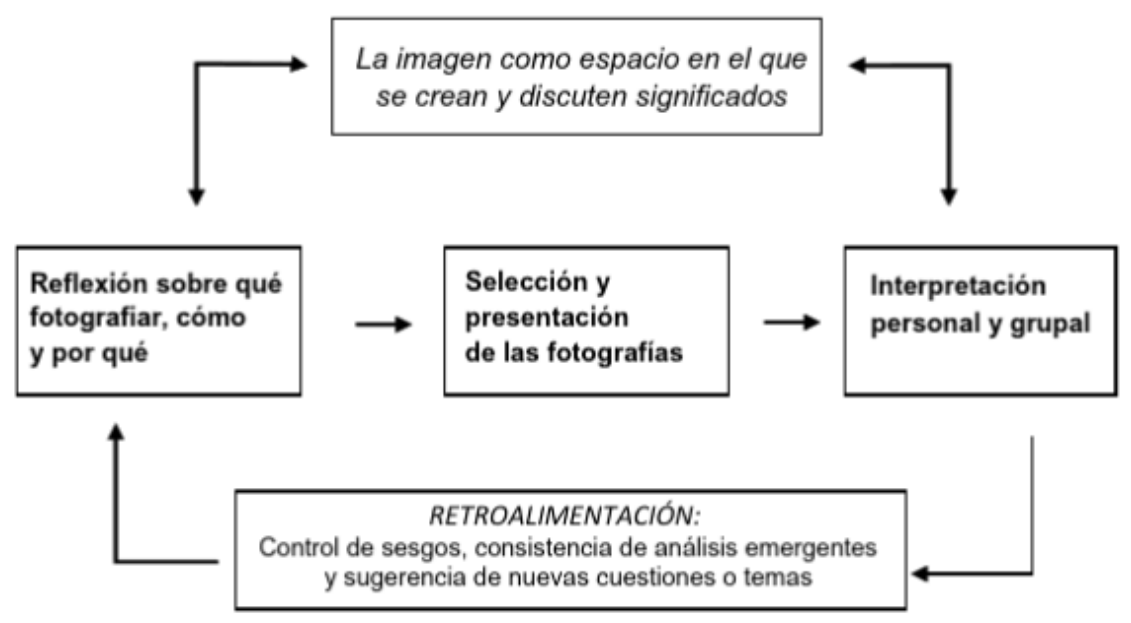

Fig. 3. Procedimiento de investigación con fotografías para la construcción de narraciones audiovisuales

Fuente: Rayón y de las Heras (2012)

El trabajo de campo se lleva a cabo durante tres cursos académicos, destacando la recogida de dos tipos de datos: 1) La producción de imágenes por parte de los estudiantes y la construcción de narraciones audiovisuales colectivas por el grupo-clase (perspectiva "emic"). 2) La observación participante en las aulas y la observación no participante en los recreos para identificar las relaciones en diferentes espacios y momentos de la jornada escolar (perspectiva "etic"). Todas las sesiones de aula y los momentos de recreo fueron registrados en vídeo para su posterior transcripción.

Se utiliza el método de análisis de contenido con las más de 900 fotografías estudiadas, por considerarse adecuado para analizar una muestra con grandes cantidades de datos (Bell, 2001; Lutz \& Collins, 1993; Rose, 2001; Van Leeuwen \& Jewitt, 2001). Concretamente, se procede de la siguiente manera:

1. Formular reglas para la codificación e identificar categorías de análisis: Se atienden a las dimensiones de significación de la imagen:

a) El contenido de las fotografías (plano denotativo), se identifican personas, lugares, espacios y objetos de su entorno que aparecen en las representaciones del alumnado, recogiendo los más significativos y relevantes en sus narraciones.

b) Los significados que otorgan a las fotografías (plano connotativo y afectivo), captados en los registros de vídeo de todas las sesiones de aula y las notas del diario de campo. 
De estos discursos surgen las categorías de análisis vinculadas a los acontecimientos, acciones y emociones más significativas en sus vidas y experiencias escolares.

c) Refinamiento de categorías, poniendo en relación el contenido de la imagen y sus significados.

2. Interpretación de los discursos emergentes en las narraciones fotográficas. Se realiza un análisis longitudinal donde se evidencian cómo van mejorando las relaciones entre los estudiantes, así como la modificación de sus puntos de vista e ideas. En el análisis de datos, se utilizó el software NVivo para la organización, gestión, análisis y triangulación de los datos. Las etapas y acciones más relevantes del análisis de datos se representan en la figura 4.

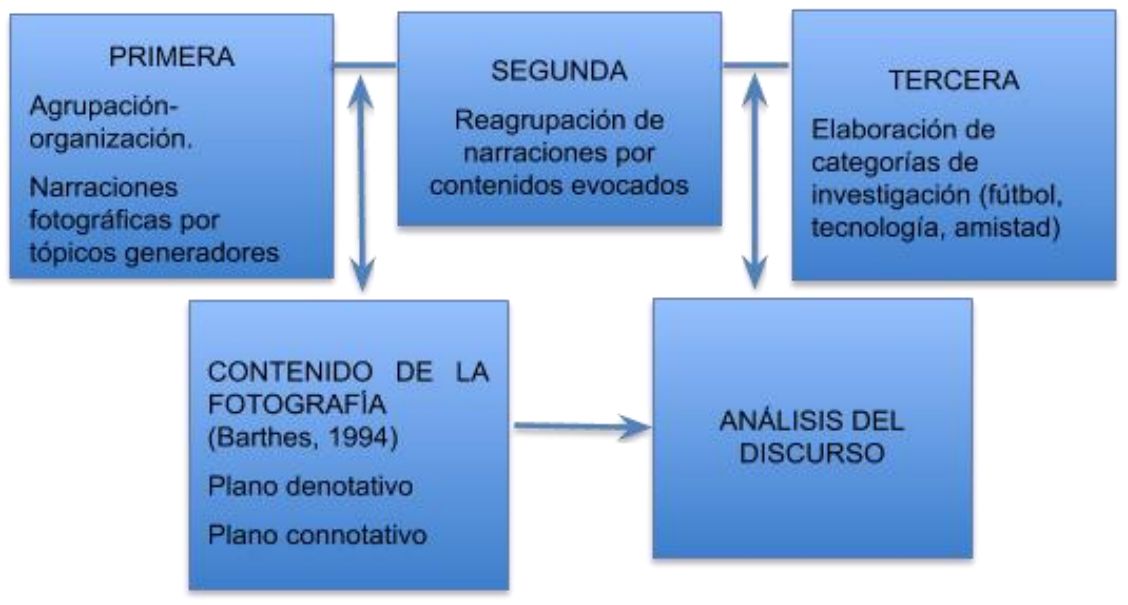

Fig.4. Etapas del proceso de análisis de los datos

Fuente: Elaboración propia

Las conclusiones más relevantes del proyecto se concretan en torno a una serie de constructos que permiten entender el universo significados que dan sentido, condicionan y configuran las relaciones interculturales entre el alumnado culturalmente diverso: el fútbol, la tecnología y el valor de la amistad en la escuela. En torno a ellos, las situaciones de construcción de narraciones visuales llevaron al alumnado a compartir experiencias e intereses y, consecuentemente, a un mayor conocimiento mutuo.

\section{Pautas para estudios posteriores y aplicabilidad en otros contextos}

La foto-elicitación aplicada conlleva un tipo de indagación educativa en la formación del profesorado orientada a identificar y sistematizar un corpus de conocimiento sobre qué teorías, creencias y visiones tienen los estudiantes en prácticas docentes con respecto a la enseñanza y el aprendizaje al inicio del Practicum, y cómo pueden ser enriquecidas y sometidas a un contraste para su mejora a través del proceso participativo constitutivo de la misma. Esto irá permitiendo acumular un conocimiento que avale un modelo de Practicum más reflexivo, aportado por el uso de la fotografía, para evocar significados y sentido como punto de partida para abordar conceptos erróneos que podrían dificultar su aprendizaje de unas didácticas efectivas. Sugerimos además que las discusiones sobre creencias preexistentes se puedan acompañar de reflexiones acerca de su viabilidad en las otras materias de enseñanza o componentes educativos, abriéndolas a los distintos componentes de las comunidades educativas. Los procesos de foto-elicitación también pueden orientarse al desarrollo del pensamiento práctico de los docentes en ejercicio, mediante su deliberación participativa en el Practicum. 
La incorporación al referido procedimiento de la indagación narrativa fotográfica supone la apertura de perspectivas por parte de los participantes quienes desde sus conocimientos experienciales pueden retroalimentar los existentes de naturaleza teórica y práctica. A través de estos procedimientos, pueden incorporarse a la teorización los puntos de vista de los participantes sobre el contenido de la mediación entre grupos culturales diversos, 0 sobre otros temas, y se pueden establecer vínculos sólidos en las relaciones entre los escolares o las personas de diferentes culturas, permitiendo el diálogo desde sus propios marcos de referencia que, en su apertura, pueden encontrarse y conocerse. Un conocimiento sobre las relaciones socio-culturales que puede orientar y justificar el diseño de programas de educación intercultural. Así mismo puede guiar o cuestionar las políticas educativas. Nuestros proyectos de investigación y otros trabajos citados ponen de relieve que la foto-elicitación y la narración fotográfica son procedimientos que posibilitan la vinculación entre la teoría y la práctica en esa doble vertiente, comprender y sistematizar cuestiones y problemas educativos y, desde ahí, tener incidencia en la política educativa y, en general, en las políticas públicas. A ello volveremos aludir en las conclusiones.

Todo lo argumentado previamente tiene mayor alcance, ya que estos procedimientos pueden aplicarse a cualquier asunto educativo y en diferentes contextos. A título de ejemplo, a la formación de otros profesionales de la educación: pedagogos, educadores sociales, psicopedagogos, entre otros, y en diversos campos como la educación inclusiva o la educación especial. En algunos, la aplicación ya se ha dado.

\section{Conclusiones}

Teniendo presente la literatura revisada y los proyectos presentados en el capítulo, así como otros realizados por el grupo de investigación, sostenemos que la foto-elicitación y la narración fotográfica son novedosos procedimientos aplicables tanto en la investigación como en la práctica profesional, posibilitan relacionar e integrar los diferentes tipos de conocimiento y, de esta forma, salvar la distancia apreciable entre la teoría y la práctica. Porque no sólo permiten una mayor y mejor captación y comprensión de la realidad, en nuestro caso la educativa, sino la vivencia de sus cualidades propias, esto es, al saber en acción en nuestra existencia, y, por tanto, al desarrollo profesional y personal. Su aplicación en las vertientes heurística y didáctica conlleva ya progreso metodológico y cognitivo.

Ahora bien, la foto-elicitación y la narración fotográfica presentarán las limitaciones que se derivan de los paradigmas de la investigación que las orientan, que son diversos. Además, se ha señalado la dificultad en el análisis de datos, profundos y complejos, de identificar, relacionar e integrar las categorías, siendo evidenciada la limitación en las publicaciones. De ahí que, desde nuestro punto de vista, sea preciso fundamentar los procedimientos, en el paradigma de la investigación participativa articulado por Heron y Reason (1997). Al insertarse estos dos procedimientos en los marcos naturales, las dificultades que, a veces, surgen en la replicación interna y externa de los datos tienen su incidencia en la fiabilidad de los hallazgos. Esta limitación está presente en el proyecto de innovación docente, al no haber podido obtener un número adecuado de registros visuales.

Nuestros proyectos han aportado evidencia que confirma las potencialidades de la fotoelicitación y la narración fotográfica, establecidas en el marco conceptual del capítulo, en los dos casos investigados, posibilitando la observación profunda, el recuerdo y la reflexión en relación con la realidad vivida en un centro educativo socio-culturalmente diverso y, en menor medida, en el Practicum de la formación de maestros. La foto-elicitación, en el último caso, ha permitido a la alumna captar y fijar realidades que eran significativas, interrogarse sobre ellas y hacerlo de forma participativa, comprender los fundamentos teóricos de los comportamientos y acciones, haciendo aflorar el conocimiento tácito de su tutora, al tiempo que ésta traía a su conciencia las teorías, creencias y valores de su enseñanza, compartiéndolos con aquella, e incrementar la reflexión conjunta y la toma de decisiones sobre su práctica. 
No obstante, estos resultados requieren replicación, por el motivo señalado y por ser un proyecto de innovación. Sin embargo, la evidencia que aporta es consonante con la de otros trabajos (Mitchell et al., 2010; Savva \& Erakleous, 2018; Vigo \& Soriano, 2014). La indagación narrativa, en el primer caso, nos ha permitido llegar a obtener dimensiones relevantes de las realidades vividas y conceptualizadas por los participantes, siendo sometidas a un proceso de re-significación, clave para el cambio de las prácticas docentes y las relaciones entre los alumnos desde sus preconcepciones, valores y acciones, con una progresiva contribución a la mejora de la práctica docente y de la convivencia intercultural. Sus resultados aportan evidencia acorde con la de los trabajos de Allen et al. (2020), Moss $(2010,2011)$ y Moss et al. (2007), que muestran que los niños, cuando narran, hacen conexiones culturales con las fotografías y encuentran intereses comunes que les capacitan para conocerse y empezar a apreciarse.

La foto-elicitación contribuye a la comprensión profunda de las realidades objeto de los estudios de casos, puede identificar cualidades que lleven a la generación de hipótesis o al desarrollo de teorías, así como a la prueba de las mismas, permitiendo el despliegue de la teoría normativa de la educación. Se sitúa en la dinámica indicada por Schwandt y Gates (2018) de indagación en lo empírico para refinar lo teórico y sobre lo teórico para comprender lo empírico. Por último, la narración fotográfica con los grupos de discusión nos abre las puertas a un conocimiento intersubjetivo de la realidad, donde se escuchen diferentes voces que aportan múltiples visiones y puntos de vista sobre un fenómeno, como hemos comprobado desde un enfoque de investigación participativo.

\section{Referencias}

Aldridge, J. (2013). Identifying the barriers to women's agency in domestic violence: The tensions between women's personal experiences and systemic responses. Social Inclusion, 1(1), 312. http://dx.doi.org/10.17645/si.v1i1.109

Ardèvol, E. (2006). La búsqueda de una mirada. Barcelona: UOC.

Austin, J. (1981). Cómo hacer cosas con palabras. Barcelona: Paidós.

Bach, H. (1998). A visual narrative concerning currículum, girls, and photography. Alberta: Qual Institute.

Bach, H. (2007). Composing a Visual Narrative Inquiry. In D. J. Clandinin (Ed.). Handbook of Narrative Inquiry. Mapping a Methodology (pp. 280-307). London: Sage. https://dx.doi.org/10.4135/9781452226552

Banks, M. (2007). Using visual data in qualitative Research. London: SAGE.

Barbour, R. (2013). Los grupos de discusión en investigación educativa. Madrid: Morata

Barthes, R (1994). El susurro del lenguaje Más allá de la palabra y de la escritura. Barcelona: Paidós.

Bautista, A. (2009). Relaciones interculturales en educación mediadas por narraciones audiovisuales. Comunicar, 33, 149-156. https://doi.org/10.3916/c33-2009-03-006

Bautista, A. (2010). Desarrollo tecnológico y educación. Madrid: La Torre.

Bautista, A. (2012). Knowledge generated by audiovisual narrative action research loops, Educational Action Research, 20(3), 423-437. https://doi.org/10.1080/09650792.2012.697405

Bautista, A. (2013a, Abril 4). Instruir, pero también formar. El País. Recuperado de: https://elpais.com/elpais/2013/04/03/opinion/1364997141 478189.html

Bautista, A. (2013b). La indagación narrativa visual en la práctica educativa. Educación y Futuro, 29, 69-80. 10.1080/09650792.2012.697405.

Bautista, A. (2019). (Coord.). La fotografía en la formación del profesorado. Madrid: Narcea.

Bautista, A. (Dir.). (2016-2017). La formación del alumnado del Grado de Maestro de Educación Primaria mediante sesiones de foto-elicitación en el Practicum [Proyecto de Innovación Docente 2016-23]. Universidad Complutense, Madrid. 
Bautista, A., Limón, M. R., Oñate, M. P., \& Rostand, C. (2016). Funciones de la fotografía en las relaciones interculturales entre familias inmigrantes. Revista Complutense de Educación, 27(1), 75-93. http://dx.doi.org/10.5209/rev RCED.2016.v27.n1.45115

Bautista, A., Rayón, L., \& de las Heras, A. M. (2012). Valor de los registros audiovisuales en educación intercultural. Comunicar, 39, 169-176. https://doi.org/10.3916/C39-2012-03-07

Bautista, A., Rayón, L., \& de las Heras, A. M. (2018). Imágenes experienciales y foto-elicitación en la formación del profesorado, Educatio Siglo XXI, 36(2), 135-162. https://doi.org/10.6018/j/333001

Bautista, A., Rayón, L., \& de las Heras, A. M. (2020). Use of Photo-elicitation to evoke and solve dilemmas that prompt changes in Primary School teachers' visions, Journal of New Approaches in Educational Research, 9(1), 137-152. https://doi.org/10.7821/naer.2020.1.499.

Bell, P. (2001). Content Analysis of Visual Images. In T. Van Leeuwen \& C. Jewitt (Eds.), Handbook of Visual Analysis (pp. 10-34). London: SAGE.

Blumer, H. (1982). El interaccionismo simbólico: Perspectiva y método. Barcelona: Hora.

Boucher, M. L. (2018). Interrogating whiteness: using photo-elicitation to empower teachers to talk about race. In M. L. Boucher (Ed.), Participant empowerment through photo-elicitation in ethnographic education research (pp. 201-225). http://doi.org/10.1007/978-3-319-64413-4 10

Cano, A. (2008). Técnicas conversacionales para la recogida de datos en investigación cualitativa: El grupo de discusión (I). Nure Investigación, 35, 1-4. Recuperado de: https://www.nureinvestigacion.es/OJS/index.php/nure/article/view/417

Carrington, S., Allen, K., \& Osmolowski, D. (2007). Visual narrative: a technique to enhance secondary students' contribution to the development of inclusive socially just school environments-lessons from a box of crayons. Journal of Research in Special Educational Needs, 7(1), 8-15. https://doi.org/10.1111/j.1471-3802.2007.00076.x

Collier, J. (1957). Photography in Anthropology: A report on two experiments. American Anthropologist, 59(5), 843-859.

Copes, H., Tchoula, W., Brookman, F., \& Ragland, J. (2018). Photo-elicitation interviews with vulnerable populations: Practical and ethical considerations. Deviant Behavior, 39(4), 475 494. https://doi.org/10.1080/01639625.2017.1407109

Etherington, K. (2007). Ethical Research in Reflexive Relationships. Qualitative Inquiry, 13(5), 599616. doi:10.1177/1077800407301175

Grimmet, K. (2018). Using photo-elicitation to break the silence. In M. L. Boucher (Ed.), Participant empowerment through photo-elicitation in ethnographic education research (pp. 71-92). http://doi.org/10.1007/978-3-319-64413-4 4

Han, C. S., \& Oliffe, J. L. (2016). Photovoice in mental illness research: A review and recommendations. Health, 20(2), 110-126. https://doi.org/10.1177/1363459314567790

Harper, D. (2002). Talking about pictures: a case for photo elicitation. Visual Studies, 17(1), 13-16. https://doi.org/10.1080/14725860220137345

Heron, J., \& Reason, P. (1997). A participatory inquiry paradigm. Qualitative Inquiry, 3 (3), 274-294. https://doi.org/10.1177/107780049700300302

Ibáñez, J. (1986). Más allá de la sociología. El grupo de discusión: Técnica y crítica (2ª ed.). Madrid: Siglo XXI.

Ibáñez, J. (1992). Más allá de la sociología: el grupo de discusión: teoría y crítica. Madrid: Siglo XXI.

Jenkins, H. (2008). Convergence Culture: La cultura de la convergencia de los medios de comunicación. Barcelona: Paidós.

Kahu, E. R., \& Picton, C. (2020). Using photo elicitation to understand first-year student experiences: Student metaphors of life, university and learning. Active Learning in Higher Education. https://doi.org/10.1177/1469787420908384

Lapenta, F. (2011). Some theoretical and methodological views on photo-elicitation. In E. Margolis \& L. Pauwels (Eds.), The Sage handbook of visual methods (pp. 201-213). Los Ángeles: Sage. 
Lemon, N. (2006). Using visual narratives for reflection. AARE Conference.

Lutz, C., \& Collins, J. (1993). Reading National Geographic. Chicago: University of Chicago.

Mannay, D. (2017). Métodos visuales, narrativos y creativos en investigación cualitativa. Madrid: Narcea.

Marková, I., Linell, P., Grossen, M., \& Salazar, A. (2007). Dialogue in Focus Groups: Exploring Socially Shared Knowledge. London: Equinox.

McNutt, J. (2013). Art therapy as a form of visual narrative in oncology care. In A. C. Malchiodi (Ed.), Art Therapy and Health Care (pp.127-135). London: The Guilford Press.

Mitchell, C., Dillon, D., Strong-Wilson, T., Pithouse, K., Islam, F., O'Connor, K., \& Cole, A. (2010). Things fall apart and come together: Using the visual for reflection in alternative teacher education programmes. Changing English, 17(1), 45-55. https://doi.org/10.1080/13586840903557068

Moss, J. (2011). Understanding visual and intertextual approaches in pedagogical and curriculum research: a pretext. International Journal of Inclusive Education, 15 (4), 379-388. https://doi.org/10.1080/13603110902838805

Moss, J. (2010). Visual methods: the exposure of exclusion and inclusion. In R. Hampe, Multimodalität in den künstlerischen therapien (pp. 359-370). Berlin: Frank \& Timme.

Moss, J., Deppeler, J., Astley, L., \& Pattinson, K. (2007). Student researchers in the middle: using visual images to make sense of inclusive education. Journal of Research in Special Education Needs, 7(1), 46-54. doi: 10.1111/j.1471-3802.2007.00080.x

Panofsky, E. (1995). El significado de las artes visuales. Madrid: Alianza.

Peirce, Ch. S. (1986). La ciencia de la semiótica. Buenos Aires: Nueva Visión.

Pink, S. (2007). Doing visual ethnography: Images, media and representations in research (2 ${ }^{\text {nd }}$ ed.). London: SAGE.

Pink, S. (2009). Doing sensory ethnography. London: SAGE.

Porto, L., \& Ruiz J.A. (2014). Los grupos de discusión. En K. Sáenz \& G. Támez, Métodos y técnicas cualitativas y cuantitativas (pp. 253-273). México: Tirant.

Rapley, T. (2007). Doing conversation, discourse and document analysis. London: Sage.

Rayón, L., \& de las Heras, A. M. (2012). Etnografía, conocimiento y relaciones interculturales. En A. Bautista y H. M. Velasco (Coords.). Antropología audiovisual: medios e investigación en educación (pp. 68-99). Madrid: Trotta

Rose, G. (2001). Visual methodologies. An introduction to the interpretation of visual materials. London: SAGE.

Savva, A., \& Erakleous, V. (2018). Play-based art activities in early years: Teachers' thinking and practice. International Journal of Early Years Education, 26(1), 56-74.

Schwandt, T. A., \& Gates, E. F. (2018). Case study methodology. In N. K. Denzin \& Y.S. Lincoln (Eds.), The Sage handbook of qualitative research (pp. 341-358). Thousand Oaks, CA: Sage.

Serrano, A., \& Revilla, J., \& Arnal, M. (2016). Narrar con imágenes: entrevistas fotográficas en un estudio comparado de "resiliencia" social y resistencia ante la crisis. Revista de Metodología de las Ciencias Sociales, 35, 71-104. DOI5.2016.17169

Sestito, S. F., Rodriguez, K. L., Saba, S. K., Conley, J. W., Mitchell, M. A., \& Gordon, A. J. (2017). Homeless veterans' experiences with substance use, recovery, and treatment through photo elicitation. Substance Abuse, 38(4), 422-431. DOI:10.1080/08897077.2017.1356422

Simons, H. (2011). El estudio de caso: teoría y práctica. Madrid: Morata.

Smith, E. (2015). Of fish and goddesses: Using photo-elicitation with sex workers. Qualitative Research Journal, 15(2), 241-249. https://doi.org/10.1108/QRJ-01-2015-0006

Stake, R. E. (1998). Investigación con estudios de caso (5ª ed.). Madrid: Morata.

Van Leeuwen, T., \& Jewitt, C. (2001). Handbook of Visual Analysis. London: SAGE. 
Vigo, M. B., \& Soriano, J. (2014). Prácticas de enseñanza y aprendizaje creativo para una educación inclusiva en la formación inicial del profesorado: experiencias de investigación. Revista de Educación Inclusiva, 7(1), 30-45. Recuperado de: https://revistaeducacioninclusiva.es/index.php/REl/article/view/161/155

Williams, B., Anderson, A. S., Barton, K., \& McGhee, J. (2012). Can theory be embedded in visual interventions to promote self-management? A proposed model and worked example. International journal of nursing studies, 49(12), 1598-1609. https://doi.org/10.1016/j.ijnurstu.2012.07.005

Wright, T. (2016). Photo-elicitation. In The photography handbook (pp.154-174). New York: Routledge.

\section{Notas biográficas}

Laura RAYÓN RUMAYOR. Profesora Titular en el Departamento de CC de la Educación de la UAH hasta octubre del 2020. En la actualidad, Profesora Titular en el Departamento de Estudios Educativos de la Universidad Complutense de Madrid. Miembro del Grupo de Investigación consolidado Desarrollo Tecnológico, Exclusión Sociocultural y Educación (UCM-941445). Investigadora principal de dos proyectos I+D (Consejería de Educación de la JCLM, EM2005-003 y EM2008-002). Ha participado en proyectos I+D+i en los últimos diez años (EDU2014-57103-R, EDU2011-23380, EDU2008-03218EDU), publicado diversos artículos y capítulos de libros sobre el uso de registros fotográficos y audiovisuales en la investigación cualitativa en la educación inclusiva e intercultural, y la formación del profesorado. Profesora Invitada en el Departamento de CCSS de la Universidad Loughbrough (Reino Unidos) en el 2013.

María Jesús ROMERA IRUELA. Profesora Titular del Departamento Estudios Educativos de la Universidad Complutense de Madrid. Miembro del grupo de investigación Desarrollo Tecnológico, Exclusión Social y Educación. Ha participado en diversos proyectos de innovación docente en los que se ha incorporado la foto-elicitación y ha colaborado en varias publicaciones que comunican investigaciones en las que se ha aplicado dicha técnica. Es autora de diversas publicaciones científicas. Sus líneas de investigación son: Epistemología y Metodología de la investigación pedagógica, Foto-elicitación y Documentación pedagógica.

Ana María de las HERAS CUENCA. Profesora Ayudante Doctor del Departamento de Estudios Educativos de la Universidad Complutense de Madrid. Miembro del grupo de investigación Desarrollo Tecnológico, Exclusión Sociocultural y Educación. Ha participado en diversos proyectos de investigación, financiados por convocatorias competitivas de ámbito nacional, en los que se estudian el valor y las posibilidades de la foto-elicitación y las narraciones audiovisuales en investigación educativa. Es autora de diversas publicaciones sobre dicha temática. Sus líneas de investigación se centran en el uso de los recursos tecnológicos para favorecer la educación intercultural e inclusiva y la formación del profesorado.

Alba TORREGO GONZÁLEZ. Profesora Ayudante Doctor del Departamento de Estudios Educativos de la Universidad Complutense de Madrid. Miembro del grupo de investigación Desarrollo Tecnológico, Exclusión Sociocultural y Educación. Ha sido integrante de distintos proyectos de investigación europeos y nacionales sobre tecnología y formación del profesorado. Es autora de diversas publicaciones sobre investigación cualitativa y, en concreto, sobre el análisis del discurso multimodal en entornos digitales. Sus líneas de investigación se centran en la alfabetización mediática en la formación del profesorado.

Antonio BAUTISTA GARCÍA-VERA. Catedrático de Universidad en el Departamento de Estudios Educativos de la Universidad Complutense de Madrid. Director del grupo de investigación consolidado de dicha Universidad, titulado Desarrollo Tecnológico, Exclusión Social y Educación (referencia: 941445), evaluado como Bueno por la Agencia Estatal de Investigación del Ministerio de Ciencia, Innovación y Universidades del Gobierno de España en julio de 2017. Ha coordinado el libro La fotografía en la formación del profesorado, donde se desarrollan conceptualmente los procedimientos de foto-elicitación y narración fotográfica. 